\title{
Characterization of polyamide powders for determination of laser sintering processability
}

\author{
Leander Verbelen $^{a 1}$, Sasan Dadbakhsh ${ }^{b}$, Michael Van den Eynde $^{a}$, Jean-Pierre Kruth ${ }^{b}$, \\ Bart Goderis ${ }^{c}$, Peter Van Puyvelde ${ }^{a}$ \\ ${ }^{a}$ KU Leuven - University of Leuven, Department of Chemical Engineering, Leuven, Belgium \\ ${ }^{\mathrm{b}} \mathrm{KU}$ Leuven - University of Leuven, Department of Mechanical Engineering, Leuven, Belgium \\ ${ }^{\mathrm{c}} \mathrm{KU}$ Leuven - University of Leuven, Department of Chemistry, Leuven, Belgium
}

\begin{abstract}
With the increasing use of laser sintering for the production of end-use parts, there is considerable interest in developing new and improved polymer materials for this technique. Due to the complexity of the process, however, materials are subject to very specific requirements in order to be easy processable. To gain a better understanding of these material requirements, this study investigates the currently most widely used material family: polyamides. Four commercial polyamide sintering grades, including two polyamide-12 grades, one polyamide- 11 and one polyamide- 6 grade, are characterized, using a new screening approach that encompasses all material properties essential for laser sintering. These include powder characteristics, melt flow, and solidification behavior of the polymer. The study reveals several particular characteristics of polyamides that explain the current popularity of this material family for laser sintering, and may be used as a guideline for finding new materials for the process.
\end{abstract}

Keywords: Laser sintering, Polyamide, Powder flow, Melt rheology, Polymer crystallization

\section{Introduction}

Laser sintering is a form of Additive Manufacturing in which parts are built layer-bylayer by selectively fusing powdered material $[1,2]$. Upon deposition, a powder layer is preheated, which is then followed by the fusion of selected regions that are heated by a laser. Subsequently, another layer of powder is spread, and the procedure is repeated until the entire part or set of parts is fabricated. The additive nature of this process enables increased part complexity, low volume production and even completely customized products [3].

In contrast to other Additive Manufacturing technologies, laser sintering allows the processing of almost any material that consolidates upon heating, including polymers, metals and even ceramics [4,5]. Additionally, parts produced by laser sintering can reach material properties that are close to those obtained by other manufacturing processes, such as injection molding [6,7]. In practice, however, this

\footnotetext{
${ }^{1}$ Corresponding author. Celestijnenlaan 200F, 3001 Leuven, Belgium. Tel.: +32 16321545 . E-mail address: leander.verbelen@cit.kuleuven.be (L. Verbelen)
} 
is not currently the case, as many materials show limited processability or result in inferior parts. The focus of this study will therefore be on the processability of polymer materials in laser sintering, with emphasis on the polyamide family.

\section{Polymers and laser sintering}

\subsection{Laser sintering of polyamide}

As polyamides are currently the most widely used polymers for laser sintering, most of the published work has focused on these materials, including mainly polyamide12 (PA12) in pure or reinforced form [7-18], but also polyamide-11 (PA11) [7,19-22] and polyamide-6 (PA6) $[23,24]$. Work on other polymers is limited, but mainly considers polystyrene [25-27], polycarbonate [28-30] and various polyaryletherketones $[8,31,32]$.

In general, polyamides are a family of polymers in which repeating units are linked by amide groups. Characteristic for polyamide formation, is the condensation reaction of an amine and an acid [33]:

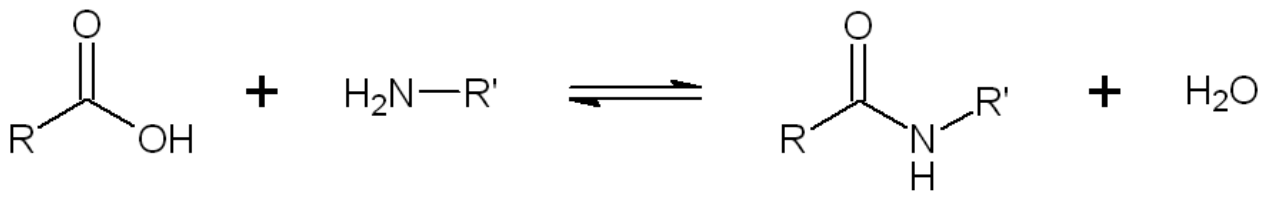

where $R$ and $R^{\prime}$ are alkyl group chains. The polycondensation of polyamides is an equilibrium reaction and unless chain stabilizers are added, chains remain reactive and new equilibria can be formed, depending on environmental conditions such as temperature and humidity $[33,34]$. Especially in the molten state these reactions readily occur, but also in the solid state reactions are possible [35].

During laser sintering, the polyamide material is kept at elevated temperatures for long times, under a dry nitrogen purge. Therefore, the molecular weight increases through postcondensation reactions, and this has important consequences for both processing and recycling of the material. Many authors investigate these changes in molecular weight of sinter polyamides using either the melt flow rate (MFR) [36- 43], solution viscosity [37], melt rheology $[37,41,44]$, or gel permeation chromatography (GPC) $[39,44]$.

\subsection{Material requirements for laser sintering}

There are several factors that may prevent successful processing of a polymer in laser sintering [7,45-47]. This section gives an overview of these factors and ways to evaluate them through experimental techniques.

\subsubsection{Powder properties}

The first step in a laser sintering cycle is the deposition of a powder layer on the build area. These layers typically have a thickness of 100 to $150 \mu \mathrm{m}$, which limits the 
maximum applicable particle size. Moreover, the powder should have good flowability in order to allow consistent deposition of thin, homogeneous layers of powder, with high packing density $[7,45]$. In principle, good powder flow is attained when interparticle adhesion and friction are low. Therefore, smooth particles with high sphericity are preferable for laser sintering, while flow enhancing additives such as silicas are often added to further enhance powder flow $[7,8,18]$.

Several methods exist to measure powder flow $[48,49]$, and several have been used to investigate flowability of sinter powders [50-52]. However, parameters obtained for powder flow are highly dependent on the measurement method. This means that there is not always a direct link between the measured parameters and the actual flowability in the sintering process. Recently, however, a new powder flowmeasuring device was introduced by our group that uses a deposition technique similar to the one used in laser sintering machines [53].

\subsubsection{Melting and coalescence}

Next to the deposition of powder layers, proper fusion of powder particles is crucial in order to obtain dense parts $[5,6]$. As no mechanical pressure is applied during laser sintering this fusion is often restricted, and full density is difficult to attain. The viscous sintering of polymer powders can be described by several models. Frenkel [54] proposed the following model:

$$
\frac{x^{2}}{R}=\frac{2 \Gamma}{3 \eta_{0}} t
$$

where $x$ and $R$ are respectively necking and particle radius, $\Gamma$ and $\eta_{0}$ surface tension and zero-shear viscosity of the polymer melt and $t$ the sintering time. The model is however only valid for the initial stages of sintering of two adjacent, perfectly spherical particles. Nevertheless, also extended sintering models $[55,56]$ show that the main parameters involved are the surface tension and the zero-shear viscosity of the polymer melt, with high surface tension and low viscosity resulting in high coalescence rates.

The surface tension of polymer melts is hard to determine, especially for polyamides $[57,58]$. Moreover, in comparison to the zero-shear viscosity, the surface tension is only a weak function of temperature and polymer type $[59,60]$ and therefore less conclusive for judging material sinterability. Consequently, the main parameter of interest is the zero-shear viscosity.

Only limited viscosity data exists for polyamide sintering grades. Haworth et al. [44] and Drummer et al. [37] obtained viscosity data for the PA12 grade PA2200 using steady and oscillatory shear measurements respectively. The majority of melt flow data found for sinter polyamides, however, is obtained using melt flow rate methods (MFR) [36,38-43]. The shear rate probed by such a measurement though depends on many factors, including the material viscosity itself, and thus no accurate zero-shear values can be obtained. 
Apart from viscosity measurements, another method to predict sintering behavior is direct visualization of the coalescence on a hot stage microscope. Some authors visualized the coalescence for sintering powders and compared these to predictions of different models for viscous sintering [61,62]. However, since necking dimensions of irregularly shaped particles are ill defined, modeling these systems is difficult.

\subsubsection{Crystallization and solidification}

Eventually, the sintered material cools down and solidifies. However, due to the layer-by-layer nature of laser sintering and the complex temperature distribution in builds, the resultant shrinkage of the material is often not homogeneous. This makes the process very prone to curling and distortion problems, which is one of the main issues encountered when testing new polymers on sintering machines. It is also decisive for the economy of the process, as curling may cause builds to crash [7].

For semi-crystalline polymers like PA12, especially the large shrinkage step upon crystallization can be detrimental [63]. To postpone crystallization and minimize thermal gradients during sintering, each powder layer is usually preheated to just below the melting onset of the polymer. Hence, the more distant the crystallization onset is from this preheating temperature, the more supercooling is allowed before crystallization initiates, which results in more homogenous shrinkage of the parts. Therefore, the distance between the melting and crystallization points has been used extensively to give an indication of the processability of semi-crystalline polymers in laser sintering, and these are therefore widely investigated using differential scanning calorimetry (DSC) $[6-9,16,18,39,40,43,62,64]$.

Apart from postponing shrinkage, having a generally low shrinkage is of course also beneficial for laser sintering, as this reduces the potential for warping. However, actual shrinkage data for sintering materials are scarce. This is most likely due to practical difficulties encountered in dilatometric measurements on molten polymers [65]. Most applicable setups measure volume changes under large pressures (PVT), which then have to be extrapolated to atmospheric pressure in order to be relevant for laser sintering. This was, for example, done by Rietzel et al [66] who obtained PVT data for PA12 - PA2200 using a piston-die technique.

\section{Experimental work}

The aim of this study is to gain a better understanding of the material requirements for polymer laser sintering. Therefore, four commercial polyamide grades are investigated by using a new screening methodology that encompasses the complete process chain in laser sintering, and the material properties involved in each step. 


\subsection{Materials}

The four polyamide grades that are selected for this study are listed in Table 1 . One of the most widely used sinter powders, trade name PA2200, is compared to three other commercial polyamide powders.

Table 1: Polyamide powders investigated in this study.

\begin{tabular}{lll}
\hline Polymer & Trade name & Manufacturer \\
\hline polyamide-12 & PA2200 $^{\circledR}$ & EOS GmbH \\
polyamide-12 & Orgasol $^{\circledR}$ Invent Smooth & Arkema S.A. \\
polyamide-11 & Rilsan $^{\circledR}$ Invent Black & Arkema S.A. \\
polyamide-6 & Sinterline $^{\mathrm{TM}}$ & Solvay S.A. \\
\hline
\end{tabular}

\subsection{Methods}

To eliminate influencing by moisture, all samples are vacuum dried for 24 hours at $80^{\circ} \mathrm{C}$ prior to each measurement, and all measurements at elevated temperatures are performed in dry nitrogen atmosphere. Each measurement was conducted three times to confirm reproducibility.

\subsubsection{Powder properties}

Particle size and morphology are investigated using Scanning Electron Microscopy (SEM, Philips XL 30), and laser diffraction (Spraytec with wet dispersion accessory, Malvern) using water as dispersant. Results of the latter are averaged over approximately 3 minutes after steady state in transmission is reached. To then characterize powder flow, a home-built setup is used which mimics powder flow in a laser sintering machine [53]. In this setup, powder layers of a defined thickness are deposited with a recoating blade. The weight of the layers is then measured to calculate the packing density of the layer, resulting in a measure for powder flow directly relevant for laser sintering. For the measurements in this study, layers of 120 $\mu \mathrm{m}$ are deposited at a recoating speed of $14 \mathrm{~cm} / \mathrm{s}$, and the average layer density $\rho_{\text {layer }}$ is determined from 20 subsequently deposited powder layers. The volumetric packing density $\rho_{\text {packing }}$ is then calculated by dividing this layer density by the material density of the powder $\rho_{\text {mat }}$ obtained through Archimedes' method (ISO 1183-1).

\subsubsection{Melting and coalescence}

To determine zero-shear viscosities, rheological measurements are performed on a rotational rheometer (AR2000-ex, TA Instruments), equipped with electrically heated plates, diameter $25 \mathrm{~mm}$. Powder tablets are prepared using a plate press (Collin $200 \mathrm{E}$ ) by compressing powder at a slightly elevated temperature of $80^{\circ} \mathrm{C}$ and a pressure of 100 bar. The use of these tablets facilitates sample loading and improves measurement consistency. The coalescence behavior of the powders is also directly visualized on a microscope (Olympus BX41), using a shear cell for heating (Linkam 
CSS450). Coalescence is visualized at a magnification of $20 \mathrm{x}$ and heating rate of $10^{\circ} \mathrm{C} / \mathrm{min}$, to allow comparison with the DSC measurements.

\subsubsection{Crystallization and solidification}

The melting and crystallization transitions of the materials are studied using differential scanning calorimetry (DSC) (Q2000, TA Instruments). Samples of $7 \pm 0.5$ $\mathrm{mg}$ are heated at $10^{\circ} \mathrm{C} / \mathrm{min}$, followed by immediate cooling at the same rate. Apart from the transitions found in DSC, also the material expansion and shrinkage is studied. A home-built adapter [67] with silicon oil as confining fluid is used in combination with a thermomechanical analyzer (TMA) (Q400, TA Instruments). With this technique, volumetric changes upon melting and crystallization can be studied under atmospheric pressure, and powders can be measured without premelting. Measurements are performed at a heating rate of $0.5^{\circ} \mathrm{C} / \mathrm{min}$, followed by 5 minutes equilibration time and subsequent cooling at $0.5^{\circ} \mathrm{C} / \mathrm{min}$. These low rates minimize thermal gradients within the sample, and allow comparison to the very low cooling rates applied during laser sintering.

\section{Results and discussion}

\subsection{Powder properties}

\subsubsection{Particle size and morphology}

Figure 1 shows SEM images and Table 2 summarizes the particle size distribution parameters for the four investigated polyamide powders. The size distribution and morphology of PA12 - PA2200 is consistent with reports in literature [45,62], as the powder consists of relatively spherical particles with a narrow size distribution around $60 \mu \mathrm{m}$. This morphology is the result of a solution-precipitation process in ethanol at elevated temperature, and $\mathrm{TiO}_{2}$ and silicas are added for improved whiteness and flowability $[68,69]$.

The other PA12 grade Orgasol consists of rather smooth, near spherical particles, with a particle size distribution around $40 \mu \mathrm{m}$ [45]. The cauliflower-shaped morphology is the direct result of the polymerization process used [70,71]. The PA11 and PA6 materials on the other hand consist of rough particles with sharp edges, which probably result from a milling step [71]. The average particle size of PA11 Rilsan is around $45 \mu \mathrm{m}$, with a significant fraction of smaller particles present. In addition, PA11 - Rilsan contains black pigment, most likely carbon black, to improve laser absorption. Compared to the other polyamides, PA6 - Sinterline contains larger particles with sizes up to $110 \mu \mathrm{m}$, but the average size is still around $60 \mu \mathrm{m}$. 

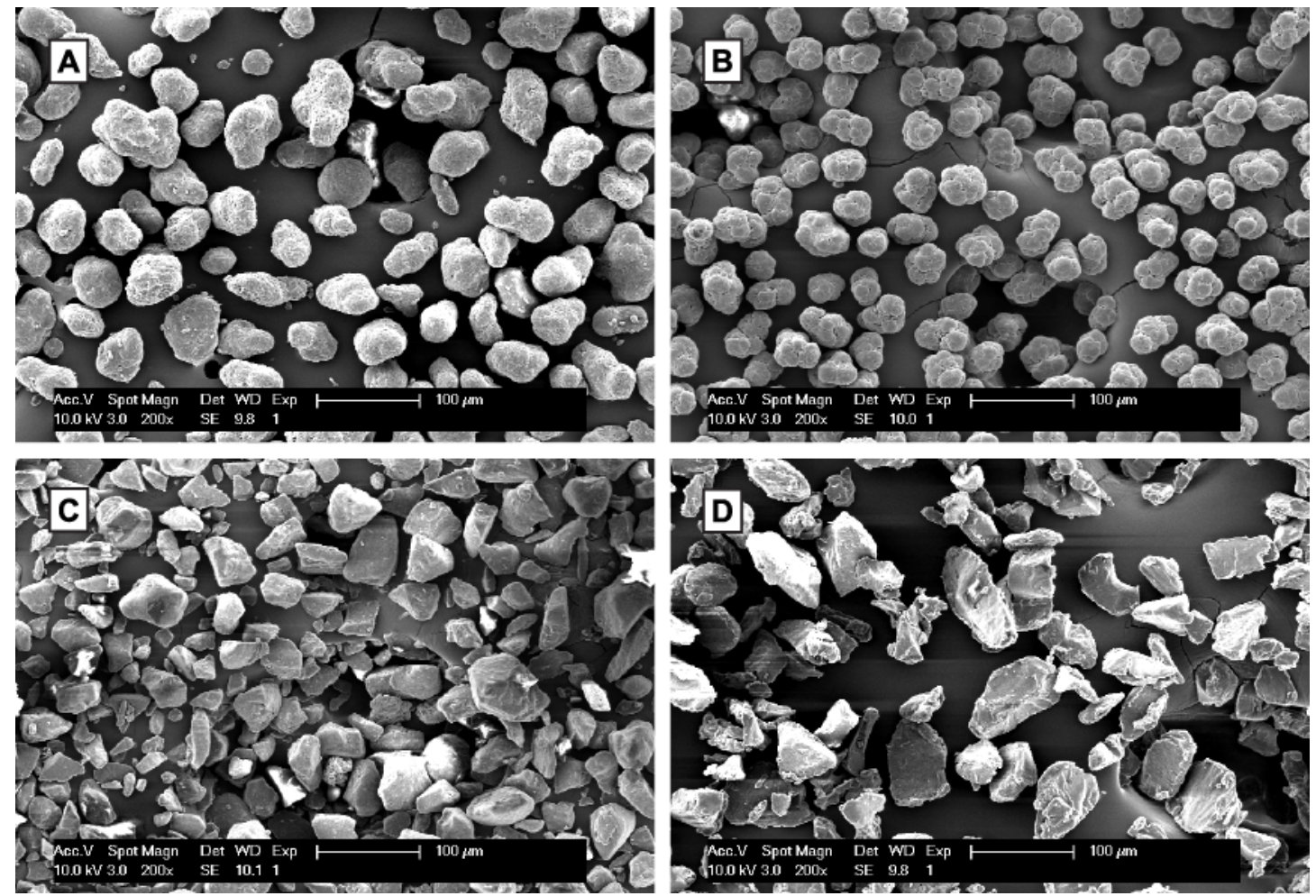

Figure 1: SEM images of PA12 - PA2200 (A), PA12 - Orgasol (B), PA11 - Rilsan (C) and PA6 - Sinterline (D).

Table 2: Particle size distribution and powder flow parameters for all polyamide powders. Standard deviations are given for the packing densities.

\begin{tabular}{lrrrrrr}
\hline & $\begin{array}{r}\mathrm{D}_{10} \\
(\mu \mathrm{m})\end{array}$ & $\begin{array}{r}\mathrm{D}_{50} \\
(\mu \mathrm{m})\end{array}$ & $\begin{array}{r}\mathrm{D}_{90} \\
(\mu \mathrm{m})\end{array}$ & $\begin{array}{r}\rho_{\text {mat }} \\
\left(\mathrm{g} / \mathrm{cm}^{3}\right)\end{array}$ & $\begin{array}{r}\rho_{\text {layer }} \\
\left(\mathrm{g} / \mathrm{cm}^{3}\right)\end{array}$ & $\begin{array}{r}\rho_{\text {packing }} \\
(\%)\end{array}$ \\
\hline PA12 - PA2200 & 38.8 & 58.6 & 88.3 & 1.07 & 0.47 & $44 \pm 5$ \\
PA12 - Orgasol & 31.9 & 42.3 & 56.5 & 1.03 & 0.50 & $49 \pm 4$ \\
PA11 - Rilsan & 20.6 & 44.2 & 80.1 & 1.06 & 0.61 & $58 \pm 5$ \\
PA6 - Sinterline & 26.9 & 57.9 & 107.2 & 1.18 & 0.53 & $45 \pm 3$ \\
\hline
\end{tabular}

\subsubsection{Powder flow}

Table 2 shows the material densities $\rho_{\text {mat }}$, and the average layer densities $\rho_{\text {layer }}$ obtained through the methods described in 3.2.1. The measured material densities resemble values found in literature $[33,71]$. The resulting packing densities $\rho_{\text {packing }}$ give an indication on the powder flowability and are estimates of the actual values in laser sintering machines. Of course, the latter also depend on temperature and recoating mechanisms and thus may deviate in practice.

In general, the flowability of all powders is high and no layer defects are observed. The packing density of PA12 - Orgasol is slightly higher compared to PA12 - PA2200, which probably results from its higher sphericity and smaller particle size. The PA6 powder shows a packing density comparable to the two PA12 powders. Surprisingly, the rough PA11 - Rilsan powder has a significantly higher packing density than the others. The flowability of this powder appears to be very high, which could stem 
from additives, like carbon black or silicas, reducing inter-particle friction. The high packing could then be the result of the high flowability, in combination with the large fraction of smaller particles present in this powder, allowing more efficient packing for the given layer thickness.

\subsection{Melting and coalescence}

\subsubsection{Rheology of the melt}

In general, the zero-shear viscosity of a polymer can be obtained by measuring its flow curve, which gives viscosity as a function of shear rate. Typical polymers are shear-thinning materials, which results in decreasing viscosities above a certain critical shear rate. However, as no shear flow is applied during laser sintering, the parameter of interest is the plateau value at low shear rates, i.e. the zero-shear viscosity. By applying the Cox-Merz rule [72], the zero-shear viscosity can in principle be obtained using either steady or oscillatory shear. However, oscillatory measurements require very long sampling times at lower frequencies, making them less suitable for determining zero-shear values. Therefore all measurements shown are conducted under steady shear conditions.

For time stable polymers, the zero-shear behavior can be evaluated by measuring the flow curve at different temperatures. However, it is found that many of the polyamides in this study show time dependent behavior due to postcondensation. For these materials, the zero-shear viscosity is determined by measuring the viscosity as a function of time at different constant shear rates. Curves that are measured at shear rates below the critical shear rate will overlap, which means that the zero-shear viscosity is obtained. Figure 2 shows the resulting zero-shear viscosities as a function of time for all samples, at three different isothermal temperatures each. All the measurements are conducted at shear rates between $0.005 \mathrm{~s}^{-1}$ and $0.01 \mathrm{~s}^{-1}$, as these were usually found to be safely within the zero-shear plateau, while still above the sensitivity limits of the rheometer.

Data for PA12 - Orgasol could simply be fitted using a constant average value. The data for the other polyamides was fitted using an adapted version of the model proposed by Acierno et al. [73]:

$$
\log \eta_{0}=\log \eta_{00}+a\left(1-\exp \left(-t / t_{x}\right)\right)
$$

where $\eta_{00}$ is the zero-shear viscosity at time equal to zero, $a$ the logarithmic viscosity increase and $t_{x}$ a characteristic time constant. Assuming the postcondensation reactions follow second order kinetics, this leads to single exponential growth of the viscosity up to characteristic time $t_{x}$. After time $t_{x}$, the kinetics dramatically slow down because of the increased molecular weight, and diffusion of reactive end groups becomes the driving mechanism. This leads to the plateau formation that is particularly visible for the high temperature data in Figure 2. The advantage of using viscosity measurements to investigate postcondensation behavior, rather than direct molecular weight measurements such as GPC, is that the changes in molecular weight as a function of time and temperature can readily be determined. 

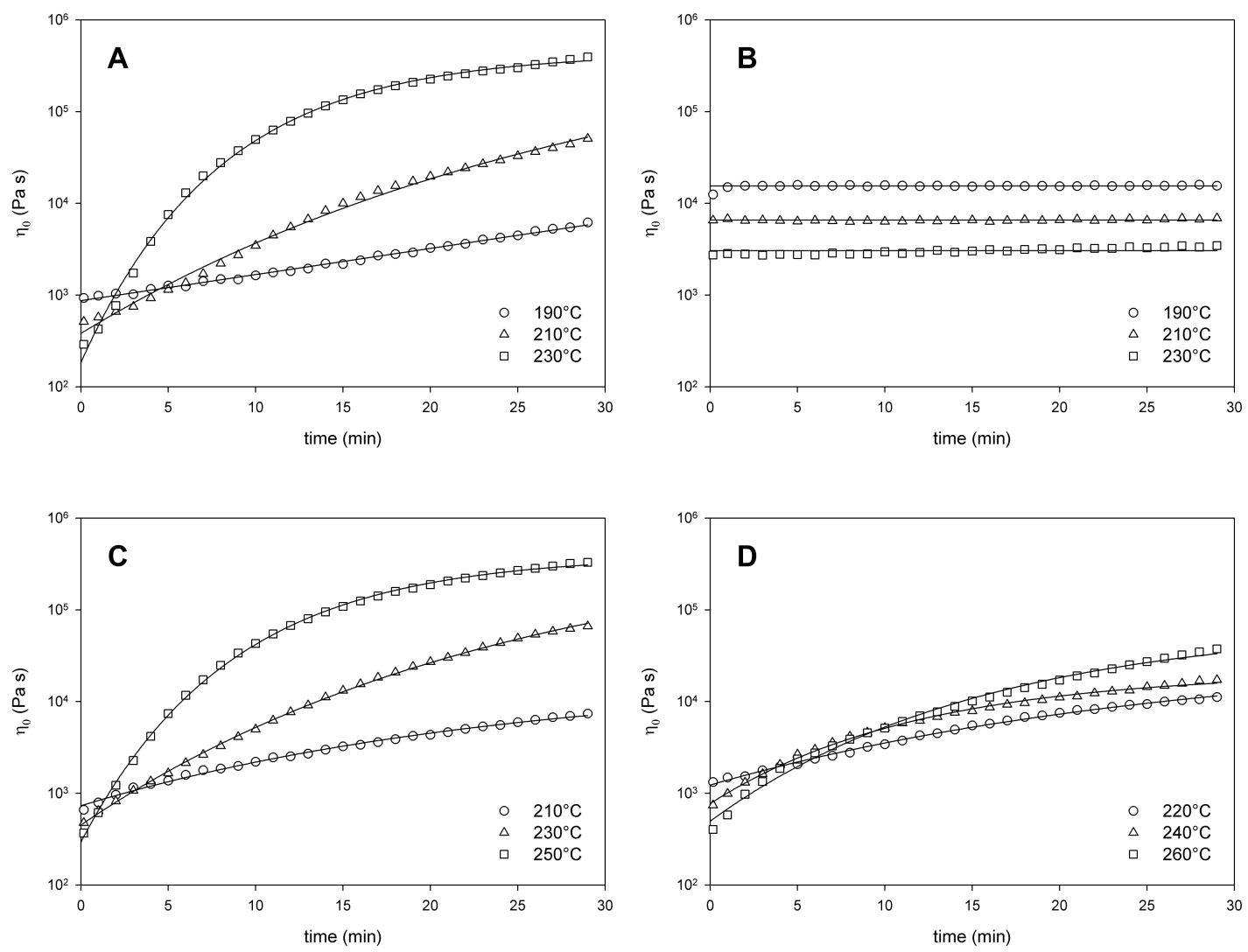

Figure 2: Zero-shear viscosity vs. time at different temperatures for PA12 - PA2200 (A), PA12 - Orgasol (B), PA11 - Rilsan (C) and PA6 - Sinterline (D).

From the data in Figure 2 it appears that, apart from PA12 - Orgasol, all materials show significant postcondensation behavior, especially at higher temperatures. PA12 - PA2200 and PA11 - Rilsan show the most substantial viscosity increases. PA12 Orgasol on the other hand, shows no change in viscosity at all. Only at the highest investigated temperature, a negligible increase is visible. This means that the polymer chains in this PA12 grade have most likely been stabilized, for example by end-capping.

As the heating time in laser sintering is very short, coalescence happens in a narrow time span. Therefore, mainly the starting values of the viscosity are crucial. These initial zero-shear viscosities $\eta_{00}$ are displayed in Figure 3 as a function of temperature. Three samples are measured for each material at each temperature, and the average values and standard deviations are plotted. The data is fitted using an Arrhenius relation:

$$
\eta_{00}=A \exp \left(\frac{E_{a}}{R T}\right)
$$

where $R$ is the universal gas constant and $E_{a}$ the activation energy, of which the resulting values are listed in Table 3. 


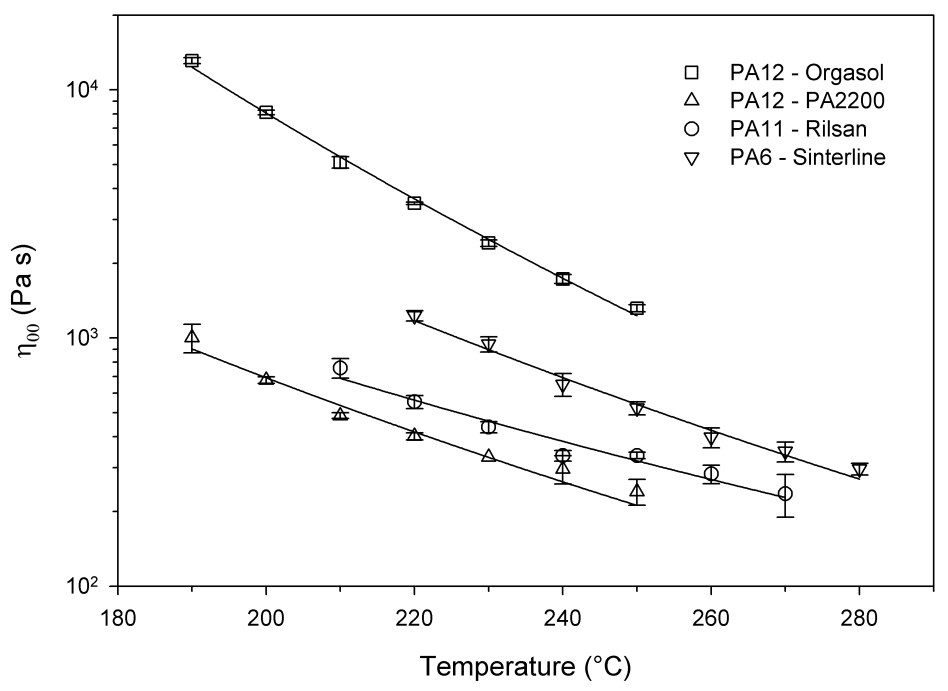

Figure 3: Initial zero-shear viscosity vs. temperature for all four polyamides.

Table 3: Activation energy for each polyamide.

\begin{tabular}{lr}
\hline & $E_{a}(\mathrm{~kJ} / \mathrm{mol})$ \\
\hline PA12 - PA2200 & 21.2 \\
PA12 - Orgasol & 33.6 \\
PA11 - Rilsan & 17.5 \\
PA6 - Sinterline & 24.1 \\
\hline
\end{tabular}

This graph shows very low initial zero-shear viscosities for all polyamides, which is highly beneficial for coalescence. Also, the activation energies for these materials are rather low, as typical literature values for polyamides range up to $60 \mathrm{~kJ} / \mathrm{mol}[34,60]$. In practice, however, these powders are usually mixed with recycled powder from previous builds, which have already undergone an undefined amount of solid state postcondensation, and thus have higher viscosities [44]. Still, the coalescence behavior will largely benefit from the presence of the low viscous virgin particles, as their high flowability will compensate for the more poorly flowing particles in the mixture.

\subsubsection{Coalescence}

Figure 4 shows the progress of coalescence for the polyamide powders on a hot stage microscope. The first image is always taken around the maximum temperature at which no changes are yet visible. As the coalescence was very slow for PA6 Sinterline, the progress over a span of $20^{\circ} \mathrm{C}$ is shown, whereas a $10^{\circ} \mathrm{C}$ span was sufficient for the other powders. As the heating rate is $10^{\circ} \mathrm{C}$ per minute, these spans correspond to 2 or 1 minute respectively. 

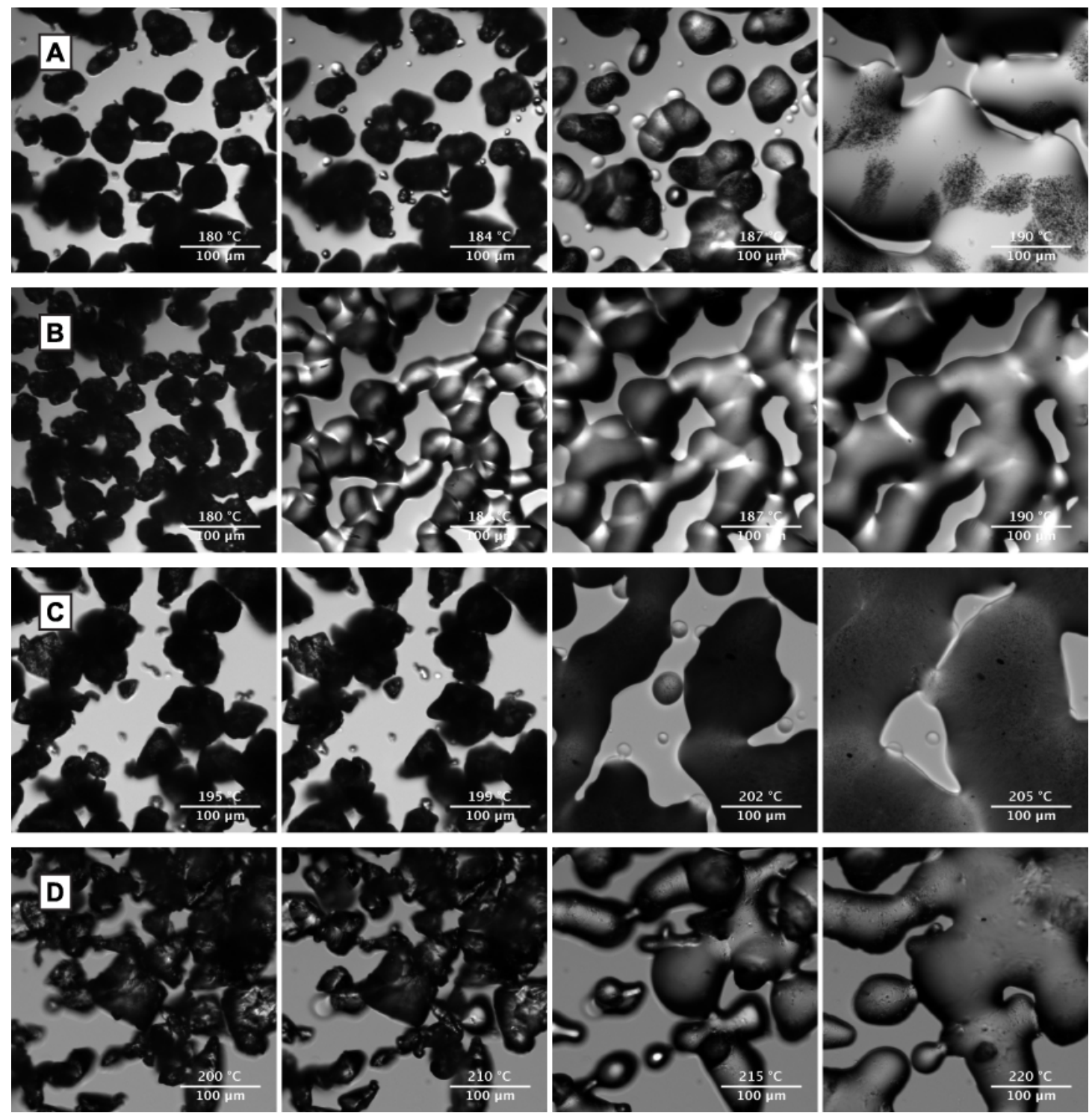

Figure 4: Coalescence on a hot stage microscope for PA12 - PA2200 (A), PA12 -

Orgasol (B), PA11 - Rilsan (C) and PA6 - Sinterline (D).

Among the analyzed polyamides, PA12 - PA2200 and PA11 - Rilsan show the most sudden coalescence, rapidly evolving to the formation of a closed film. PA12 Orgasol on the other hand shows slower coalescence due to its higher viscosity. And also PA6 - Sinterline shows very gradual coalescence, which in this case is caused by the very broad melting peak observed in DSC (see further). In general, all investigated powders coalesce well if sufficient heat is applied. However, as stated above, in practice powders are mixed with recycled fractions, making the actual coalescence behavior more difficult to predict.

Further observations include the significant presence of small-sized polymer particles in both PA12 - PA2200 and PA11 - Rilsan, and the appearance of dark spots consisting of very small non-melting particles in the PA12 - PA2200 molten film. These probably result from the fact that this powder is coated with $\mathrm{TiO}_{2}$ particles [62]. Also, the presence of the black pigment in PA11 - Rilsan is clearly visible. 


\subsection{Crystallization and solidification}

\subsubsection{Differential Scanning Calorimetry}

As stated in the introduction, a large distance between melting and crystallization peaks in DSC is a good indication of the tendency of a material to warp or curl during laser sintering. Figure 5 shows DSC measurements for the different polyamides. The maximum temperature of the DSC cycle is varied in order to study how the amount of heating affects the behavior of the samples.

It is found that for PA12 - PA2200, an increased heating temperature results in a significant postponing of the crystallization onset. This is because the higher temperature enhances postcondensation reactions, resulting in increased molecular weight and melt viscosity, and therefore slower crystallization kinetics. PA6 Sinterline shows a similar effect. However, as PA12 - Orgasol does not postcondense, the crystallization peak stays constant in all measurements.

Surprisingly, even though PA11 - Rilsan shows similar postcondensation characteristics to PA12 - PA2200 in viscosity measurements, the crystallization behavior is only slightly affected in DSC. This could be because of an additive acting as nucleating agent, compensating for the effect of increased molecular weight. This can be linked to the observation of small spherulites in this material. Bai et al [15] observed a similar effect for PA12 filled with carbon nanotubes. Nevertheless, the crystallization peaks of all postcondensing polyamides are less sharp compared to PA12 - Orgasol, indicating gradual crystallization kinetics for these materials.

Another observation is that when PA12 - PA2200 is only heated to $190^{\circ} \mathrm{C}$, an early gradual crystallization onset is seen, and similar behavior could also be observed for the other polyamides (not shown in these graphs). This is due to self-seeding, as not all crystals are fully molten and the remaining crystals then act as nucleation sites for crystallization upon cooling. This effect is rather common for polyamide, as even in the melt some hydrogen bonds can remain fixed, resulting in effective nucleation sites upon cooling [33]. It is therefore crucial to apply sufficient laser energy during processing in order to fully melt the material and destroy all nuclei to prevent premature crystallization.

Apart from the crystallization peaks, also the melting peaks give important indications on sinterability of materials. Apart from PA6 - Sinterline, all polyamides show very sharp melting peaks with high enthalpies of fusion. This is due to the high crystal perfection of the virgin materials, and is very advantageous for sintering. A high enthalpy of fusion prevents melting of excess particles adjacent to the scanned regions [69]. Also, the large amount of crystalline phase prevents unsintered powder from becoming sticky when kept for long times above the glass transition. Undesirable caking of this powder can therefore be avoided. Moreover, the sharp melting onset and narrow melting range allow the use of high preheating temperatures, followed by rapid and complete melting upon laser impact. 

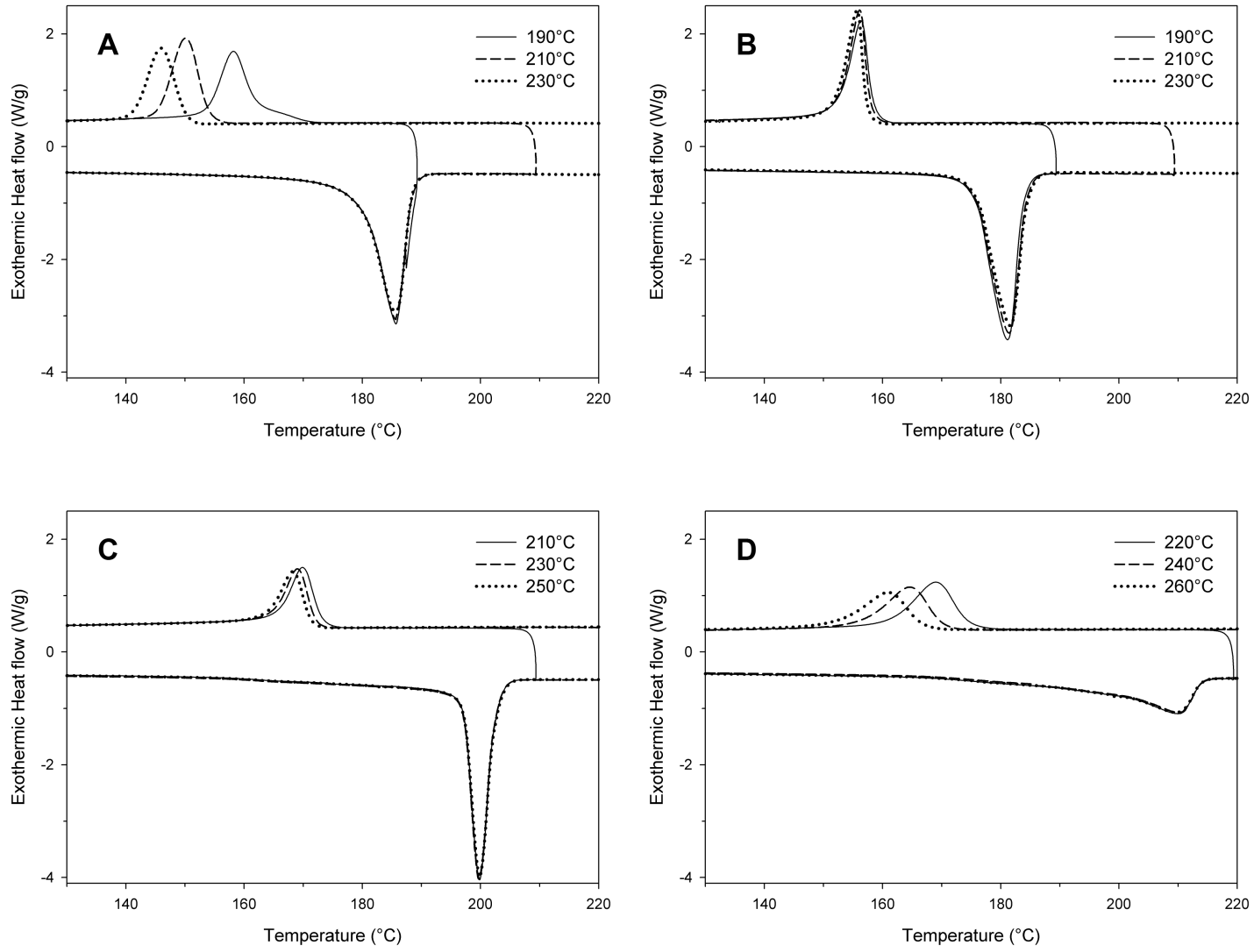

Figure 5: DSC measurements with different maximum heating temperatures for PA12 - PA2200 (A), PA12 - Orgasol (B), PA11 - Rilsan (C) and PA6 - Sinterline (D).

In general, the windows between melting and crystallization onsets are large for all studied materials, especially for PA12 - PA2200 and PA11 - Rilsan. The very gradual melting onset of PA6 - Sinterline may however obstruct the selection of a high preheating temperature for this material. The fact that polyamide melts tend to supercool to a greater degree than most polymers is commonly observed in literature [33], and could be ascribed to the complex mechanisms involved in polyamide crystal formation. This tendency to supercool gives polyamides the thermal robustness needed to cope with the very diverse thermal histories encountered in laser sintering.

\subsubsection{Shrinkage}

To further investigate the potential of the materials to warp, their dilatometric properties are measured. Figure 6 shows specific volume as a function of temperature for all polyamides. Measurements are performed directly on the virgin powders, and both heating (solid lines) and cooling (dashed lines) are shown, as is the volumetric shrinkage percentage upon crystallization. PA12 - Orgasol however contained porosity in which the confining measurement fluid could not penetrate. This affected the data upon heating, and thus only the cooling data is shown in this case. 

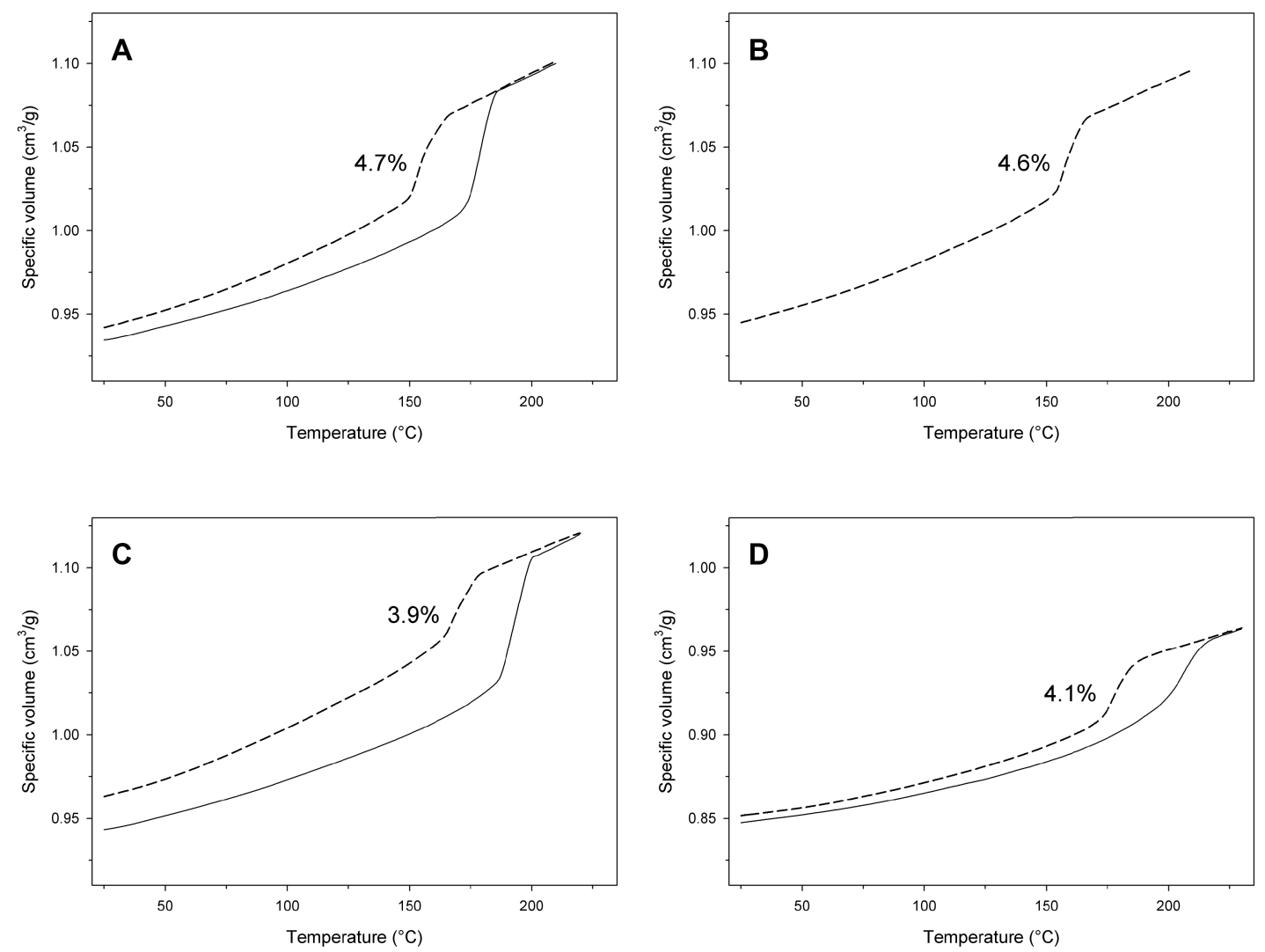

Figure 6: Dilatometric measurements of PA12 - PA2200 (A), PA12 - Orgasol (B), PA11 - Rilsan (C) and PA6 - Sinterline (D). Solid and dashed lines correspond to heating and cooling respectively.

PA12- PA2200 and PA11 - Rilsan show very large expansion steps upon melting, due to the high crystallinity of the original powder. The crystallization shrinkages upon cooling are similar among all investigated materials, and comparable to the values found by Zoller [65] for other polyamide grades. In general, the observed shrinkages are low for typical semi-crystalline polymers, as values for high-density polyethylene for example can range up to $13 \%$ [65]. Furthermore, these graphs also illustrate the large distances between melting and crystallization for the investigated materials.

It should be noted that crystallization shrinkage is strongly dependent on the amount of crystallinity formed upon cooling, and thus on the thermal history of the material. Nevertheless, DSC measurements at different cooling rates and up to different maximum temperatures hardly showed variations in crystallization enthalpy. Additionally, the curves are measured at a very low cooling rate of $0.5^{\circ} \mathrm{C} / \mathrm{min}$, which approximates the cooling rate during laser sintering. Therefore, it can be assumed that the measured volumetric changes correspond to those in the actual sintering process, meaning that these data could for example be used in models to predict part accuracy. 


\subsection{Discussion}

From the performed measurements, it is clear that all investigated polyamide powders have properties that make them suitable for laser sintering. There are nevertheless some important differences between the powders that will impact their processability. These differences will become apparent in long-term performance robustness and success rates of builds on various sintering machines. This cannot be tested in small scale sintering tests, and therefore the focus in this research is on prediction of this performance, based on material characterization.

It is found that the powder flow is good for all the investigated powders, as smooth and dense layers can be deposited without any problems. This also shows that powders with a rough morphology, like the PA6 and PA11 powders, can be used perfectly well for laser sintering, as long as the particle size distribution and powder composition are properly tuned. Coalescence and film formation upon melting also appear to be good for all powders, which is a consequence of their very low zeroshear viscosities.

The processing windows on the other hand show important differences between the investigated polyamides. Whereas PA12 - PA2200 and PA11 - Rilsan show very wide windows between melting and crystallization onsets, these windows are significantly smaller for the other grades. This means that PA12 - Orgasol and PA6 - Sinterline will be more prone to curling and have a lower tolerance for deviations from optimum processing conditions. It is also reported by Schmid et al [45] that processing PA12 Orgasol is more challenging. And Dupin [62] found significant differences as well between processing of Duraform PA and Innov PA, which are similar in characteristics to PA12 - PA2200 and PA12 - Orgasol respectively. Less difference is found in crystallization shrinkage, which is small for all investigated materials. It is likely, however, that polymers with larger crystallization shrinkage will be more challenging to sinter.

Various measurements in this study show that postcondensation of polyamide strongly affects properties that are crucial for laser sintering. The low initial melt viscosity promotes fast coalescence of the powder, whereas the increasing molecular weight results in postponing of the crystallization onset and improvement of the final mechanical performance. This behavior is also exploited in powder coating processes, for which many sintering PA11 and PA12 powders were originally developed $[33,74]$. Postcondensation reactions may also improve interlayer bonding, and thus reduce anisotropy of laser sintered parts [45].

However, postcondensation behavior also has important disadvantages for laser sintering. The solid state postcondensation of supporting powder in sintering builds leads to a significant molecular weight and viscosity build-up [38,39]. Excess reuse of this powder therefore leads to processing difficulties and rough part surfaces, commonly known as 'orange skin'. Furthermore, the variable feedstock mixture of recycled and virgin powder may be one of the main reasons for the inconsistent mechanical performance of sintered parts reported in literature [64]. 


\section{Conclusions}

In this study, different polyamide sinter powders are thoroughly characterized and material behavior is linked to expected performance in the laser sintering process. The current popularity of polyamide materials for laser sintering can be explained by the combination of powder availability, low initial zero-shear viscosity, and the low tendency to warp due to a large degree of supercooling and small crystallization shrinkage. Postcondensation behavior seems to play a major role in establishing these properties. However, this behavior is detrimental for the recyclability of the powder and the consistency of part properties. Especially with the increasing interest in using laser sintering for manufacturing rather than prototyping, these drawbacks are undesirable. Moreover, in order for laser sintering to become a widespread manufacturing technique, a larger variety of materials that can readily be processed is necessary. This may require new approaches considering material development, and improvement of the current sintering machines.

\section{Acknowledgments}

The authors acknowledge the financial support of Strategic Initiative Materials in Flanders (SIM) and the Agency for Innovation by Science and Technology Flanders (IWT).

\section{References}

[1] Deckard CR. Selective laser sintering. PhD dissertation, Department of Mechanical Engineering, University of Texas at Austin; 1988

[2] Deckard CR. Method and apparatus for producing parts by selective sintering. US patent 5017753; 1991

[3] Hopkinson N., Hague R., Dickens P. Rapid manufacturing: an industrial revolution for a digital age. Berlin: Wiley-Blackwell; 2005

[4] Kruth JP, Wang X, Laoui T, Froyen L. Lasers and materials in selective laser sintering. Assem Automat 2003; 23(4):357-71

[5] Kruth J-P., Levy G., Klocke F. Childs THC. Consolidation phenomena in laser and powder-bed based layered manufacturing. Ann CIRP 2007; 56(2)

[6] Kruth J-P, Levy G, Schnidel R, Craeghs T, Yasa E. Consolidation of polymer powders by selective laser sintering. PMI2008 Ghent, Belgium; September 2008

[7] Goodridge R.D., Tuck C.J., Hague R.J.M. Laser sintering of polyamides and other polymers. Progress in Materials Science 2012; 57:229-267

[8] Drummer D, Rietzel D, Kühnlein F. Development of a characterization approach for the sintering behavior of new thermoplastics for selective laser sintering. Proceedings of the LANE, Physics Procedia 5, 2010, p.533-542

[9] Vasquez M, Haworth B, Hopkinson N. Methods for quantifying the stable sintering region in laser sintered polyamide-12. Polymer Engineering \& Science, vol 53, issue 6, p. 1230-1240, 2013

[10] Athreya SR, Kalaitzidou K, Das S. Processing and characterization of a carbon black-filled electrically conductive nylon-12 nanocomposite produced by selective laser sintering. Material Science and Engineering A, 527(10-11):2637-42, 2010

[11] Jain PK, Pandey PM, Rao PVM. Selective laser sintering of clay-reinforced polyamide. Polymer Composites 2009; 31(4):732-43

[12] Goodridge RD, Shofner ML, Hague RJM, McClelland M, Schlea MR, Johnson RB, Tuck CJ. Processing of a polyamie-12/carbon nanofibre composite by laser sintering. Polymer Testing 2011; 30(1):94-100 
[13] Mazzoli A, Moriconi G, Pauri MG. Characterization of an aluminium-filled polyamide powder for applications in selective laser sintering. Materials and Design 28(3) (2007) 993-1000

[14] Salmoria GV, Leite JL, Paggi RA, Lago A, Pires ATN. Selective laser sintering of PA12-HDPE blends: effect of components on elastic/plastic behavior. Polymer Testing 2008; 27:654-9

[15] Bai J, Goodridge RD, Hague RJM, Song M. Carbon nanotube reinforced polyamide 12 nanocomposites for laser sintering. Proceedings of the 23th Solid Freeform Fabrication Symposium, Austin, Texas; 2012 p. 98-107

[16] Zarringhalam $\mathrm{H}$, Hopkinson N, Kamperman NF, de Vlieger JJ. Effects of processing on microstructure and properties of SLS nylon 12. Materials Science and Engineering A 435-436 (2006) 172-180.

[17] Guo Y, Jiang K, Bourell DL. Preparation and laser sintering of limestone PA12 composite. Polymer Testing 37 (2014) 210-215

[18] Dupin $S$, Lame $O$, Barrès $C$, Charmeau JY. Microstructural origin of physical and mechanical properties of polyamide 12 processed by laser sintering. European Polymer Journal 48 (2012) 1611-1621

[19] Lao SC, Yong W, Nguyen K, Moon TJ, Koo JH, Pilato L, Wissler G. Flame-retardant polyamide 11 and 12 nanocomposites: processing, morphology, and mechanical properties. Journal of composite materials, vol 44 no 25,2010

[20] Chung H, Das S. Processing and properties of glass bead particulate-filled functionally graded nylon-11 composites produced by selective laser sintering. Materials Science and Engineering A 437 (2006) 226-234

[21] Wegner A, Harder R, Witt G, Drummer D. Determination of optimal processing conditions for the production of polyamide 11 parts using the laser sintering process. International Journal of Recent Contributions from Engineering, Science \& IT, vol 3 no 1 (2015)

[22] Leigh DK. A comparison of polyamide 11 mechanical properties between alser sintering and traditional molding. Proceedings of the 23th Solid Freeform Fabrication Symposium, Austin, Texas; 2012 p. 574-605

[23] Kim J, Creasy TS. Selective laser sintering characteristics of nylon 6/clay-reinforced nanocomposite. Polymer Testing 2004; 23:629-36

[24] Zhou W, Wang X, Hu J, Zhu X. Melting process and mechanics on laser sintering of single layer polyamide 6 powder. Int J Adv Manuf Technol (2013) 69:901-908

[25] Ku CW, Gibson I, Cheung WL. Selective laser sintered castform polystyrene with controlled porosity and its infiltration characteristics by red wax. Proceedings of the 13th Solid Freeform Fabrication Symposium, Austin, Texas; 2011 p. 107-114

[26] Shi Y, Wang Y, Chen J, Huang S. Experimental investigation into the selective laser sintering of high-impact polystyrene. Journal of Applied Polymer Science, vol 108, 535-540 (2008)

[27] Dotchev KD, Dimov SS, Pham DT, Ivanov Al. Accuracy issues in rapid manufacturing CastForm patterns. Proceedings of the Institution of Mechanical Engineers; 2007, 221, p 53

[28] Shi Y, Chen J, Wang Y, Li Z, Huang S. Study of the selective laser sintering of polycarbonate and postprocess for parts reinforcement. Journal of materials - design and applications, vol 221, issue L1, p 37-42, 2007

[29] Ho HCH, Cheung WL, Gibson I. Morphology and properties of selective laser sintered bisphenol A polycarbonate. Ind Eng Chem Res 2003, 42, 1850-1862

[30] Berzins M, Childs THC, Ryder GR. The selective laser sintering of polycarbonate. CIRP Annals Manufacturing Technology, vol 45 issue 1 1996, p 187-190

[31] Schmidt M, Pohle D, Rechtenwald. Selective laser sintering of PEEK. Annals of the CIRP vol 56 issue 1 p 205-208, 2007

[32] Berretta S, Evans KE, Ghita O. Processability of PEEK, a new polymer for high temperature laser sintering (HT-LS). European Polymer Journal 68 (2015) 243-266

[33] Kohan MI. Nylon plastics handbook. Hanser/Gardner Publications 1995

[34] Laun HM. Das viskoelastische Verhalten von Polyamid-6-Schmelzen. Rheologica Acta 18, 478491 (1979)

[35] Zimmerman J. Equilibria in solid phase polyamidation. Journal of Polymer Science Part B Polymer letters. Vol 2 issue 10P, p 955-958, 1964

[36] Mielicki C, Wegner A, Wortberg J, Witt G, Gronhoff B. Prediction of PA12 melt viscosity in laser sintering by a time and temperature dependent rheological model. RTejournal - Forum für Rapid Technologie, vol.9 (2012) 
[37] Drummer D, Wudy K, Drexler M. Modeling of the aging behavior of polyamide 12 powder during laser melting process. Proceedings of the 30th international conference of the Polymer Processing Society, 2014

[38] Dotchev KD, Yusoff WA. Recycling of polyamide 12 based powders in the laser sintering process. Rapid Prototyp J 2009; 15:192-203

[39] Pham DT, Dotchev KD, Yusoff WAY. Deterioration of polyamide powder properties in the laser sintering process. J Mechanical Engineering Science 2008; 222:2163-76

[40] Yusoff WAY, Pham DT, Dotchev KD. Investigation of the thermal properties of different grades polyamide 12 (PA12) in improving laser sintering process (SLS). Applied Mechanics and Materials vols 548-549 (2014) p 294-296

[41] Martínez A, Ibáñez A, Sánchez A, León MA. Comparison of aged polyamide powders for selective laser sintering. AIP conference proceedings 1431, 5-13 (2012)

[42] Wegner A, Mielicki C, Grimm T, Gronhoff B, Witt G, Wortberg J. Determination of robust material qualities and processing conditions for laser sintering of polyamide 12 . Polymer Engineering \& Science. Vol 54, issue 7, pages 1540-1554, 2014.

[43] Gornet TJ, Davis KR, Starr TL, Mulloy KM. Characterization of selective laser sintering materials to determine process stability. Proceedings of the 13th International Solid Freeform Fabrication Symposium 2002 p 546-553

[44] Haworth B, Hopkinson N, Hitt, D, Zhong X. Shear viscosity measurements on polyamide-12 polymers for laser sintering. Rapid Prototyping Journal 19/1:28-36 2013

[45] Schmid M, Amado A, Wegener K. Materials perspective of polymers for additive manufacturing with selective laser sintering. Journal Materials Research, vol 29, no.17, 2014

[46] Shi Y, Li Z, Sun H, Huang S, Zeng F. Effect of the properties of the polymer materials on the quality of selective laser sintering parts. Journal of materials - design and applications, vol 218 issue L3 p 247-252, 2004.

[47] Evans RS, Bourell DL, Beaman JJ, Campbell MI. SLS materials development method for rapid manufacturing. Proceedings of the 16th Solid Freeform Fabrication Symposium, Austin, Texas; 2005 p. 184-196

[48] Yokoyama T. in: Masuda H, Higashitani K, Yoshida H, editors. Powder technology handbook. Taylor and Francis Group: CRC Press; 2006 p. 349-61

[49] Lumay G, Boschini F, Traina K, Bontempi S, Remy JC, Cloots R, Vandewalle N. Measuring the flowing properties of powders and grains. Powder technology vol 224, pages 19-247, 2012

[50] Amado A, Schmid M, Levy G, Wegener K. Advances in SLS powder characterization. Proceedings of the 22th Solid Freeform Fabrication Symposium, Austin, Texas; 2011 p. 438452

[51] Berretta S, Ghita O, Evans KE. Morphology of polymeric powders in laser sintering (LS): from polyamide to new PEEK powders. European Polymer Journal 59 (2014) 218-229

[52] Ziegelmeier S, Christou P, Wöllecke F, Tuck C, Goodridge R, Hague R, Krampe E, Wintermantel $E$. An experimental study into the effects of bulk and flow behaviour of laser sintering polymer powders on resulting part properties. Journal of Materials Processing Technology 215 (2015) 239-250

[53] Van den Eynde M, Verbelen L, Van Puyvelde P. Assessing polymer powder flow for the application of laser sintering. Powder Technology 286, 151-155, 2015.

[54] Frenkel J. Viscous flow of crystalline bodies under the action of surface tension. J Phys 1945; 9(5):358-91

[55] Eshelby JD, Discussion in paper by Shaler AJ, Seminar on the kinetics of sintering. Metals Trans 185:806-807, 1949

[56] Bellehumeur CT, Kontopoulou M, Vlachopoulos J. The role of viscoelasticity in polymer sintering. Rheologica Acta 1998, 37, 270-278

[57] Sauer BB, Dipaolo NV. Surface tension and dynamic wetting of polymers using the wilhelmy method - applications to high molecular weights and elevated temperatures. Journal of colloid and interface science, vol 144 issue 2, pages 527-537, 1991

[58] Sauer BB, Dee GT. Surface tension and melt cohesive energy density of polymer melts including high melting and high glass transition polymers. Macromolecules, vol 35 issue 18, pages 7024-7030, 2002

[59] Wouters M, de Ruiter B. Contact-angle development of polymer melts. Progress in Organic Coatings 48 (2003) 207-213 
[60] Brandrup J, Immergut EH, Grulke EA. (1999) Polymer Handbook, 4th ed., Wiley, New York, NY

[61] Vasquez M, Hopkinson N, Haworth B. Laser sintering processes: practical verification of particle coalescence for polyamides and thermoplastic elastomers. Proceedings of ANTEC, 2011

[62] Dupin S. Etude fondamentale de la transformation du polyamide 12 par frittage laser: mécanismes physico-chimiques et relations microstructures/propriétés. PhD dissertation, Institut national des sciences appliquées de Lyon, France. 2012

[63] Gibson I, Shi D. Material properties and fabrication parameters in selective laser sintering process. Rapid Prototyp J 1997; 3(4):129-36

[64] Bourell DL, Watt TJ, Leigh DK, Fulcher B. Performance limitations in polymer laser sintering. Physics Procedia 56 (2014) 147-156

[65] Zoller P, Walsh D. Standard pressure-volume-temperature data for polymers, CRC Press, 1995

[66] Rietzel D, Drexler M, Kühnlein F, Drummer D. Influence of temperature fields on the processing of polymer powders by means of laser and mask sintering technology. Proceedings of the 22th Solid Freeform Fabrication Symposium, Austin, Texas; 2011 p. 252262

[67] patent pending, reference number GB 1516898.2

[68] Meyer KR, Hornung KH, Feldmann R, Smigerski HJ. Method for polytropically precipitating polyamide powder coating compositions where the polyamides have at least 10 aliphatically bound carbon atoms per carbonamide group. US patent 4334056; 1982

[69] Scholten H, Christoph W. Use of a nylon-12 for selective laser sintering. US patent 6245281; 2001

[70] Loyen K, Senff H, Pauly FX. Process for the manufacture of polyamide-12 powder with a high melting point. US patent 8124686; 2012

[71] Orgasol ultra-fine powders, product information. Arkema <http://www.arkema.com>

[72] Cox WP, Merz EH. Correlation of dynamic and steady flow viscosities. Journal of Polymer Science vol 28 issue 118 p. 619-622, 1958

[73] Acierno S, Van Puyvelde P. Rheological behavior of polyamide 11 with varying initial moisture content. Journal of Applied Polymer Science, vol 97, 666-670 (2005)

[74] Mumcu S, Panoch HJ, Rueter J. Process for preparing polyamide-based, pulverulent coating compositions for high molecular weight post condensation, employing the precipitation procedure. US patent 4711925; 1987 